\title{
HUNT Gómez, CoRal Ivy. Didáctica de la Interpretación en los Tribunales de JuSTICIA. Una propuesta tecnológica. Granada: Comares, 2019, 106 pp. ISBN: 978-84-9045-853-2
}

La interpretación judicial ha acaparado el protagonismo en los últimos años al revelarse una práctica profesional descuidada por el intrusismo, las condiciones laborales y la abundancia de traducciones deficientes. Ese trasvase lingüístico que realiza el intérprete se antoja como una garantía básica, pues ya en los principios de nuestro sistema jurídico se recoge el derecho a contar con la asistencia de un mediador lingüístico. El acceso profesional a los tribunales es variopinto, pues si bien en países como en España existe cierta regulación de acceso a través de las 4 pruebas del MAEC (para las cuales se requieren 16 créditos en interpretación y 24 créditos en traducción jurídica y/o económica), en otros países como Italia el ingreso se produce a través de una simple inscripción en el tribunal bajo la figura de CTU (Consulente Tecnico d'Ufficio). En cuanto a las asociaciones que apoyan la profesión, pese a que la mayoría de las asociaciones de traductores e intérpretes recogen parcialmente aspectos dedicados a la interpretación para los servicios públicos, encontramos solo dos asociaciones dedicadas completamente al sector, la Asociación Profesional de Traductores e Intérpretes Judiciales y Jurados (APTIJ) y la Asociación de Traductores e Intérpretes Jurados de Cataluña.

Actualmente, al alcance del intérprete se encuentran diversos instrumentos que optimizan el proceso de traslación, como corpus, diccionarios bilingües, glosarios, memorias de traducción y bases de datos. Sin embargo, el conocimiento de dos esferas jurídicas, más allá del ámbito meramente lingüístico, lleva aparejada una exhaustiva preparación práctica que los actuales grados universitarios no colman, dado que dedican escasos créditos a una actividad que tiene como objetivo favorecer el acceso efectivo a los derechos básicos por parte del profano. A tal propósito, el libro que propone Ivy Coral Hunt Gómez se postula, desde un punto de vista empírico, como una recogida de recursos documentales dirigidos a mejorar las competencias del intérprete en los tribunales de justicia. La propuesta ha sido publicada por la editorial Comares en su colección Interlingua, prestigiosa editorial de Granada que acumula más de 200 títulos sobre traducción e interpretación y que concierne otras áreas humanísticas como la literatura, el derecho, la filosofía y la historia, además de las ciencias sociales. El estudio se divide en los cuatro capítulos que describimos a continuación: 
El primer capítulo apela a la necesidad de crear materiales dirigidos a la formación de la interpretación en los tribunales de justicia en España, de carácter audiovisual y de gran interés en el estudiante, pues es evidente la escasez y falta de autonomía y de autoevaluación de los ya existentes. Por ello, advierte de la exigencia de trabajar con materiales reales para enfocar la práctica al contexto tan específico que requiere la ITJ.

El segundo capítulo está dedicado a la tecnología al servicio de la enseñanza de la interpretación. A través de un repaso por las TIC en la profesión y en la formación de los intérpretes, la autora resalta los profundos cambios tecnológicos que se han producido en el seno de la profesión. A principios de los 90 aparecieron en el mercado productos de videotelefonía que provocaron la reticencia de las grandes instituciones. Sin embargo, con el tiempo Internet y los fecundos avances de la tecnología en el campo de la interpretación han favorecido el desarrollo de avanzados instrumentos de documentación y preparación terminológica que facilitan la práctica de esta actividad e, incluso, han dado lugar a un nuevo tipo de interpretación remota (IR). A ello, hay que añadir que el nuevo modelo de sociedad ha cambiado profundamente las bases del trabajo, lo cual implica un cambio en la profesión $y$, en consecuencia, en la formación; de hecho, asistimos a una didáctica posible ya desde hace varios lustros a través de grabaciones y de cintas de vídeo, o más recientemente, a través de la práctica con material audiovisual con canales específicos como Youtube. A tal respecto, la autora detalla las herramientas CAIT (Computer Assisted Interpreter Training) en la formación de intérpretes, divididas en Integrative CAIT, intelligent CAIT y Ambientes Virtuales de aprendizaje (VLE). Las primeras tienen como objetivo proporcionar material real al alumnado a través de bases de datos y repositorios con el fin de permitir la práctica de la profesión. Algunas de las más importantes son la base de datos IRIS, perteneciente a la Scuola Superiore di Lingue Moderne per Interpreti e Traduttori de la Universidad de Trieste; la base de datos MARIUS bajo la coordinación de Jesús de Manuel Jerez de la Universidad de Granada que ofrece una selectiva selección de materiales en función de parámetros como la duración o el número de palabras del discurso; la UE Speech Repository con discursos de simultánea y consecutiva en 30 idiomas clasificados por niveles y la European Parliament Interpreting Corpus (EPIC) constituida por un corpus en inglés, italiano y español a cargo de la Universidad de Boloña. Las intelligent CAIT, por su parte, encuentran respuesta en los programas utilizados para la creación de materiales didácticos personales, tales como Interprlt, Interpretations y The Black Box, todos ellos surgidos en el seno de la Universidad de Hull. Por último, los entornos virtuales han favorecido la proliferación de una gran cantidad de plataformas virtuales al servicio de la didáctica en la interpretación, como por ejemplo EVITA y Video Speech Repository 
(Universidad de Ginebra), ORCIT (financiado por la UE) y National Network for Interpreting Website e Interpreter Training Resources.

El tercer capítulo, por su parte, recoge una descripción de los recursos y materiales didácticos tecnológicos a los que se puede recurrir para la enseñanza de la interpretación. Nos encontramos ante una profundización de la interpretación para los servicios públicos (en donde se integra la interpretación en el tribunal), la cual en España empezó a tener cabida a partir de los años ochenta, fruto de los flujos migratorios. En esa línea, se exponen a título informativo algunos de los programas universitarios españoles dedicados a la ISP y diversos proyectos realizados tanto en universidades españolas (con productos como Interpreta, los materiales didácticos de la USAL bajo la dirección de Baigorri Jalón, las actividades llevadas a cabo por los grupos MIRAS y CRIT o Linkterpreting y SOS-VICS), como en ámbito europeo con Building Mutual Trust, AVIDICIUS e Interpreting in Virtual Reality, y estadounidense con Interpretapes y ACEBO.

El cuarto y último capítulo, de carácter eminentemente práctico, expone una propuesta de material didáctico a partir de material real. En este caso, y a través de un juicio encuadrado en la rama de lo penal, se elabora una actividad de interpretación compuesta inicialmente por un vídeo, en el que se explican las características de este contexto, y por una sucesión de 122 turnos que reproducen la duración del testimonio. Para facilitar el autoaprendizaje, se ha procedido a resaltar la terminología específica y se ha proporcionado una transcripción de lo proferido por las partes.

El libro que presentamos nos lleva irremisiblemente a un plano práctico de la didáctica de la ISP. Sería ocioso no destacar la fecundidad con la que se presentan los recursos y materiales que tanto el profesor de interpretación como el estudiante tienen a su alcance para la mejora de la transmisión de técnicas en el caso del primero y la adquisición de competencias por parte del segundo. La preocupación creciente por la creación de material se postula como un necesario instrumento complementario de apoyo al tiempo específico de trabajo en interpretación que los grados universitarios no logran abarcar, alejándose de una profesión que hace de la práctica y la experiencia su caballo de batalla. Por otra parte, se antoja importante una mayor publicación de materiales didácticos específicos al tratarse de una disciplina cuya literatura se ha escrito a partir de fuentes empíricas, y en donde normalmente los profesores configuran el material para sus clases, permaneciendo posterior y celosamente entre bastidores.

Por todo ello, hemos querido llevar a cabo la descripción del libro de Hunt Gómez, de ágil lectura y que recomendamos, por cierto, para promover los numerosos recursos, en ocasiones desconocidos, promovidos por 
diferentes grupos y centros de investigación, accesibles en Internet. Por último, y añadiendo una nota de color fruto de la experiencia personal del presente reseñador, la literatura sobre interpretación jurídico-judicial es rica, pero no así el material de derecho destinado a traductores e intérpretes, que se reduce a la formación otorgada en el Doble Grado en Traducción e Interpretación y en Derecho, ofertado por algunas universidades, y al título "El derecho para no juristas" de Alfred Font Barrot y José Luis Pérez Triviño, dirigido al profano en leyes. Con todo, parece no tener cabida la creación de más materiales formativos específicos para una profesión en la que no se deberá encarar solo dos espectros lingüísticos, sino también dos sistemas legales diferentes.

[RUBÉn GONZÁLEZ VALLEJO] 